\title{
Cisplatin/Paclitaxel/Bevacizumab Regimen
}

National Cancer Institute

\section{Source}

National Cancer Institute. Cisplatin/Paclitaxe//Bevacizumab Regimen. NCI Thesaurus.

Code C136241.

A chemoimmunotherapy regimen consisting of cisplatin, paclitaxel and bevacizumab that is used for the treatment of cervical cancer. 